\title{
The stress-strein state from its own weight in ground base with trapezoidal cutout
}

\author{
Elephan Agakhanov ${ }^{1, *}$, Murad Agakhanov ${ }^{2}$ and Edward Batmanov ${ }^{1}$ \\ ${ }^{1}$ Dagestan State Technical University, Imam Shamil Ave. 70, 367015, Makhachkala, Russia \\ ${ }^{2}$ Moscow State University of Civil Engineering, Yaroslavskoye shosse, 26, 129337, Moscow, Russia
}

\begin{abstract}
In order to determine the deformation of the base, the shrinkage of the structures erected on them, as well as to study the strength of the bases, it is necessary to determine the stresses in the soil massif. The stresses in the soil massif from the action of the structure are superimposed on the existing stresses in it from the action of its own weight, taking into account the excavation during the development of the pit. Therefore, the paper considers the stress-strain state of the ground base with a trapezoidal cutout under its own weight. It is shown that the effect of the own weight of the ground base with a trapezoidal cutout can be replaced by the fictitious action of the ball tensor of forced deformations and external load. At the same time, the previously known methods of replacing the own weight of the soil base by the action of fictitious surface forces, existing in the presence of rigid restrictions, are special cases of the solutions obtained in this work. In modern conditions, in relation to the total amount of accumulated professional knowledge, the volume of active information resources is increasing, and construction practice is constantly enriched with new experimental and theoretically sound accurate knowledge.
\end{abstract}

\section{Introduction}

In order to assess the deformation of the base, the shrinkage of the structures erected on them, as well as the study of the strength of the bases, it is necessary to determine the stresses from the action of the own weight of the soil [1-11].

On the available in the soil massif stress from the action of its own weight (initial stress), stress arising from the action of the structure is superimposed. The initial stress in the general case is determined by gravity (own weight of the soil) and change of these forces in the process of forming the soil massif, tectonic and seismic impacts, and other factors.

\section{State of the problem}

In this article, the conditions are established that allow us to represent the effect of the own weight of the soil in the form of the sum of the impact of surface forces and forced

\footnotetext{
* Corresponding author: muradak@mail.ru
} 
deformations. Since the feasibility of each action is limited by the possibilities of modeling techniques, the conditions presented are important for experimental problem solving.

During the period of site infrastructure works the initial stress state of the soil massif may also change, particularly as a result of dredging in the development of excavation, dewatering, ramming, or rolling the soil, etc. In this case one should speak about a modified - initial stress state of the base, which interacts further with the stresses from the building.

\section{Method of research}

Let us consider the stress-strain state of the ground base with a trapezoidal cutout, which is under the influence of its own weight, i.e. under the action of volume forces

$$
F_{x}=0, \quad F_{y}=0, F_{z}=\mathrm{g},
$$

where $\mathrm{g}=$ const is the volume weight of the soil.

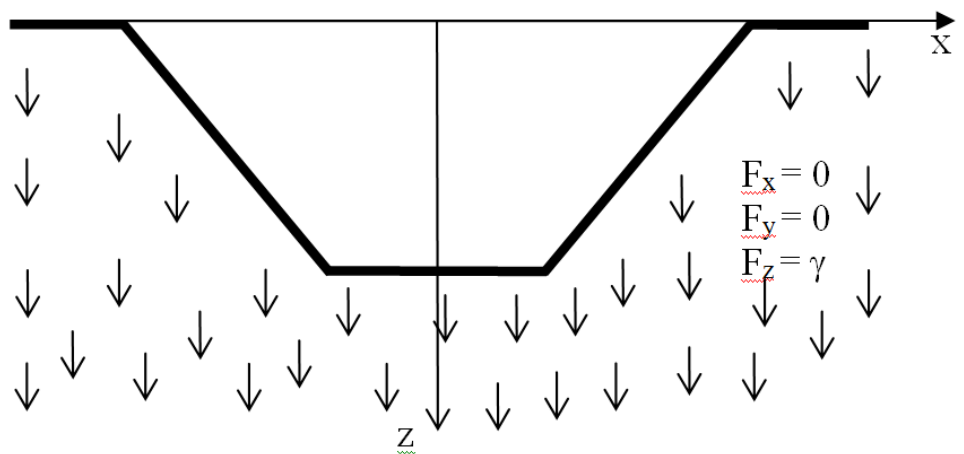

Fig. 1. Ground base with trapezoidal cutout under its own weight.

The system of equations to describe the stress-strain state in the area of the base by the action of its own weight looks like [12]

$$
\begin{gathered}
U_{i, j j}^{(\mathrm{g})}+U_{j, i j}^{(\mathrm{g})}+2 S_{, i}^{(\mathrm{g})}+\frac{F_{i}}{G}=0, \\
2 G\left[0,5\left(U_{i, j}^{(\mathrm{g})}+U_{j, i}^{(\mathrm{g})}\right)+\mathrm{d}_{i j} S^{(\mathrm{g})}\right] n_{j}=0, \\
\mathrm{~s}_{i j}^{(\mathrm{g})}=2 G\left[0,5\left(U_{i, j}^{(\mathrm{g})}+U_{j, i}^{(\mathrm{g})}\right)+\mathrm{d}_{i j} S^{(\mathrm{g})}\right],
\end{gathered}
$$

where $S^{(\mathrm{g})}=\frac{\mathrm{n}}{E} \mathrm{~S}_{i i}^{(\mathrm{g})}$ or in case $v \neq 0,5$

$$
S^{(\mathrm{g})}=\frac{\mathrm{n}}{1-2 \mathrm{n}} U_{j, j}^{(\mathrm{g})}
$$

It makes sense to obtain the possibility of stress-strain state from the given forces of its own weight in the form of the stress-strain state caused by the resultant effects of surface loads $P_{i}$ and forced deformations $\xi$. 
The stress-strain state in the area of the base under the action of the load distributed along the boundary surface and directed normally to this surface and forced deformations is described by a system of equations $[13,14]$

$$
\begin{gathered}
U_{i, j j}^{(P, \mathrm{x})}+U_{j, i j}^{(P, \mathrm{x})}+2 S_{, i}^{(P, \mathrm{x})}=0, \\
2 G\left[0,5\left(U_{i, j}^{(P, \mathrm{x})}+U_{j, i}^{(P, \mathrm{x})}\right)+\mathrm{d}_{i j} S^{(P, \mathrm{x})}\right] n_{j}=P_{i}, \\
\mathrm{~s}_{i j}^{(P, \mathrm{x})}=2 G\left[0,5\left(U_{i, j}^{(P, \mathrm{x})}+U_{j, i}^{(P, \mathrm{x})}\right)+\mathrm{d}_{i j} S^{(P, \mathrm{x})}\right],
\end{gathered}
$$

where $S^{(P, \mathrm{x})}=\frac{\mathrm{n}}{E} \mathrm{~S}_{i i}^{(P, \mathrm{x})}-\mathrm{X}$ or in case $v \neq 0,5$

$$
S^{(P, \mathrm{x})}=\frac{\mathrm{n}}{1-2 \mathrm{n}} U_{j, j}^{(P, \mathrm{x})}-\frac{1+\mathrm{n}}{1-2 \mathrm{n}} \mathrm{x} .
$$

For identical equality of displacement $U_{i}^{(\mathrm{g})} \equiv U_{i}^{(P, \mathrm{x})}$ the following conditions must be met:

$$
\begin{gathered}
2 S_{, i}^{(P, \mathrm{x})}=2 S_{, i}^{(\mathrm{g})}+\frac{F_{i}}{G}, \\
2 G S^{(P, \mathrm{x})} n_{i}=2 G S^{(\mathrm{g})} n_{i}-P_{i} .
\end{gathered}
$$

Taking into account the correlations (5) and (9), these conditions take the form

$$
\begin{aligned}
& \frac{E}{1-2 \mathrm{n}} \mathrm{x}_{, i}=-F_{i} ; \\
& \frac{E}{1-2 \mathrm{n}} \mathrm{x} n_{i}+P_{i}=0,
\end{aligned}
$$

If $U_{i}^{(\mathrm{g})} \equiv U_{i}^{(P, \mathrm{x})}$, then from (4) and (8) we get

$$
\mathrm{s}_{i j}^{(\mathrm{g})}=\mathrm{s}_{i j}^{(P, \mathrm{x})}+\mathrm{d}_{i j} 2 G\left[S^{(\mathrm{g})}-S^{(P, \mathrm{x})}\right] .
$$

Taking into account the correlations (5) and (9) we get

$$
\mathrm{S}_{i j}^{(\mathrm{g})}=\mathrm{s}_{i j}^{(P, \mathrm{x})}+\mathrm{d}_{i j} \frac{E}{1-2 \mathrm{n}} \mathrm{x} .
$$

We will rewrite the expression (13) taking into account that $P_{i}=P n_{i}$

$$
\frac{E}{1-2 \mathrm{n}} \mathrm{x}+P=0
$$


Comparing the expression (16) differentiated by i with (12) we will obtain

$$
\frac{\partial P}{\partial i}=F_{i}
$$

The expression (15), taking into account (16), takes the following form

$$
\mathrm{s}_{i j}^{(\mathrm{g})}=\mathrm{s}_{i j}^{(P, \mathrm{x})}-\mathrm{d}_{i j} P \text {. }
$$

According to the expression for volume forces (1) of (12) and (17) we have

$$
\begin{gathered}
\mathrm{x}=-\frac{1-2 \mathrm{n}}{E} \mathrm{~g} z, \\
P=\mathrm{g} z .
\end{gathered}
$$

Consequently, the determination of the stress-strain state from the given volume forces (the own weight of the soil) is reduced to the determination of the stress-strain state from the forced deformations of the ball type (temperature effect) (19) and the external surface load (20), distributed respectively according to linear and hydrostatic laws (Fig. 2). More precisely, the displacements in these problems coincide identically, and the stresses are related according to the correlation (18).

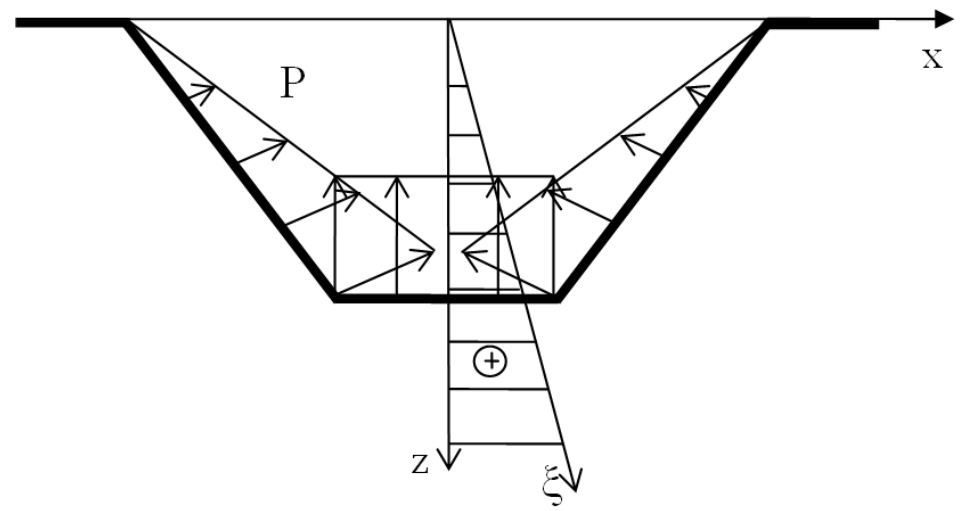

Fig. 2. The ground base with trapezoidal cutout under action of replacing loads.

The methods of experimental determination of the stress-strain state under the action of surface loads and forced deformations, to which the initial problem is reduced, are methodically developed with completeness sufficient to obtain effective solutions.

\section{Analysis of results}

Some special cases.

1. Base with flat surface. The surface load then according to (20) is zero $P=0$, hence the stress $\mathbf{S}_{i j}^{(p)}=0$ and expression (18) take the form

$$
\mathrm{s}_{i j}^{(\mathrm{g})}=\mathrm{s}_{i j}^{(\mathrm{x})}-\mathrm{d}_{i j} P=\mathrm{s}_{i j}^{(\mathrm{x})}-\mathrm{d}_{i j} \mathrm{~g} z .
$$


Under compression conditions of deformation of the base should be assumed

$$
\mathrm{e}_{x}^{(\mathrm{x})}=\mathrm{e}_{y}^{(\mathrm{x})}=0
$$

from the conditions of equivalence of the directions of ox and oy

$$
\mathbf{S}_{x}^{(x)}=\mathbf{S}_{y}^{(\mathrm{x})}
$$

Obviously, that from the forced deformations X , defined by expression (19), stresses $\mathrm{S}_{z}^{(\mathrm{x})}$ are equal to zero, i.e.

$$
\mathrm{S}_{z}^{(\mathrm{x})}=0
$$

Then taking into account (24) from expression (21) we have

$$
\mathrm{S}_{z}^{(\mathrm{g})}=-\mathrm{g} z
$$

Substituting the known correlation between the deformations $\mathrm{e}_{x}^{(\mathrm{x})}$ and stresses $\mathrm{S}_{x}^{(\mathrm{x})}$

$$
\mathrm{e}_{x}^{(\mathrm{x})}=\frac{1}{E}\left[\mathrm{~s}_{x}^{(\mathrm{x})}-\mathrm{n}\left(\mathrm{s}_{y}^{(\mathrm{x})}+\mathrm{s}_{z}^{(\mathrm{x})}\right)\right]+\mathrm{x}
$$

with expressions (19), (22), (23) and (24), after trivial transformations, we have

$$
\mathrm{S}_{x}^{(\mathrm{x})}=\mathrm{S}_{y}^{(\mathrm{x})}=\frac{1-2 \mathrm{n}}{1-\mathrm{n}} \mathrm{g} z .
$$

Taking into account (27) from expression (21) we have

$$
\mathrm{S}_{x}^{(\mathrm{g})}=\mathrm{S}_{y}^{(\mathrm{g})}=-\frac{\mathrm{n}}{1-\mathrm{n}} \mathrm{g} z .
$$

Then for the coefficient of lateral pressure of the soil we obtain

$$
\mathrm{h}=\frac{\mathrm{s}_{x}^{(\mathrm{g})}}{\mathrm{S}_{z}^{(\mathrm{g})}}=\frac{\mathrm{s}_{y}^{(\mathrm{g})}}{\mathrm{s}_{z}^{(\mathrm{g})}}=\frac{\mathrm{n}}{1-\mathrm{n}}
$$

The obtained expressions (25), (28) and (29) for stresses $\mathrm{S}_{z}^{(\mathrm{g})}, \mathrm{S}_{x}^{(\mathrm{g})}, \mathrm{S}_{y}^{(\mathrm{g})}$, and the lateral pressure coefficient of the soil coincide with the known [4]. The difference of signs in the expressions (25) and (28) is due to the fact that in soil mechanics the reverse rule of signs is accepted, and the equations in this work are written following the rules of signs accepted in the theory of elasticity.

2. We take the Poisson's ratio equal to 0.5. According to (19) the forced deformations are then $\mathrm{X}=0$, hence the stress and correlation (18) takes the form [15] 


$$
\mathrm{s}_{i j}^{(\mathrm{g})}=\mathrm{s}_{i j}^{(P)}-\mathrm{d}_{i j} P
$$

provided a flat surface

$$
\mathrm{s}_{i j}^{(\mathrm{g})}=-\mathrm{d}_{i j} P=-\mathrm{d}_{i j} \mathrm{gz} .
$$

In this case, all three normal stresses are equal, that is, the lateral pressure coefficient is equal to one and there is a uniform (hydrostatic) compression. This solution also coincides with the known [4]. If the Poisson's ratio in the expressions (28) and (29) is replaced by 0.5 , then together with (25) they represent the same solution.

3. Let the forced deformation not cause stress, i.e. ${ }^{S_{i j}^{(x)}}=0$. Then the solutions (30) and (31) used for the case 2 are acceptable for all values of the Poisson's ratio.

\section{Conclusions}

The conditions allow us to present the effect of the own weight of the soil in the form of the sum of the effects: the impact of surface forces and forced deformation. It is shown that the solutions of the problems by the presented method coincide with the previously known solutions.

\section{References}

1. G.E. Agakhanov, Scientific review 12, 733-736 (2014)

2. G.E. Agakhanov, V.B. Melekhin, Scientific review 4, 90-93 (2016)

3. E.C. Agakhanov, M.K. Agakhanov, International Journal For Computational Civil And Structural Engineering 2, 24-28 (2014)

4. V.A. Florin, Fundamentals of Soil Mechanics (Gosstroiizdat, 1959)

5. E.K. Agakhanov, M.K. Agakhanov, MATEC Web Conf. 86, 01012 (2016)

6. E.K. Agakhanov, M.K. Agakhanov, Higher education proceedings. North-Caucasus Region. Engineering sciences 1, 25 (2005)

7. G.E. Agakhanov, Scientific review, 12 (2014)

8. G.E. Agakhanov, Bulletin of Dagestan State Engineering University, 1 (2015)

9. E.K. Agakhanov, M.K. Agakhanov, Izvestiya Vuzov. Severo-Kavkazskiy region. Tekhnicheskie nauki, 1 (2005)

10. E.C. Agakhanov, M.K. Agakhanov, Industrial and Civil Construction 11, 40-44 (2015)

11. V.I. Andreev, A.S. Avershyev, International Journal for Computational Civil and Structural Engineering 9, 3 (2013)

12. E.K. Agakhanov, Bulletin of Dagestan State Technical University. Technical science 2, 39-45 (2013)

13. G.E. Agakhanov, Bulletin of the Dagestan state technical University. Technical science 3, 8-15 (2015)

14. E.C. Agakhanov, M.K. Agakhanov, Vestnik MGSU 3, 140-143 (2010)

15. E.K. Agakhanov, M.K. Agakhanov, MGSU Bulletin 3, 140-143 (2010) 